\title{
Antimicrobial Resistance and Food Animals: Influence of Livestock Environment on the Emergence and Dissemination of Antimicrobial Resistance
}

\author{
Nikola Vidovic ${ }^{1}$ and Sinisa Vidovic ${ }^{2, *}$ \\ 1 College of Pharmacy and Nutrition, University of Saskatchewan, Saskatoon, SK S7K 4H3, Canada; \\ nikola.vidovic@usask.ca \\ 2 Department of Veterinary and Biomedical Sciences, College of Veterinary Medicine, University of Minnesota, \\ Saint Paul, MN 55108, USA \\ * Correspondence: svidovic@umn.edu
}

Received: 6 January 2020; Accepted: 27 January 2020; Published: 31 January 2020

check for updates

\begin{abstract}
The emergence and dissemination of antimicrobial resistance among human, animal and zoonotic pathogens pose an enormous threat to human health worldwide. The use of antibiotics in human and veterinary medicine, and especially the use of large quantities of antibiotics in livestock for the purpose of growth promotion of food animals is believed to be contributing to the modern trend of the emergence and spread of bacteria with antibiotic resistant traits. To better control the emergence and spread of antimicrobial resistance several countries from Western Europe implemented a ban for antibiotic use in livestock, specifically the use of antibiotics for growth promotion of food animals. This review article summarizes the recent knowledge of molecular acquisition of antimicrobial resistance and the effects of implementation of antibiotic growth promoter bans on the spread of antimicrobial resistant bacteria in animals and humans. In this article, we also discuss the main zoonotic transmission routes of antimicrobial resistance and novel approaches designed to prevent or slow down the emergence and spread of antimicrobial resistance worldwide. Finally, we provide future perspectives associated with the control and management of the emergence and spread of antimicrobial resistant bacteria.
\end{abstract}

Keywords: antimicrobial resistance; livestock; growth promotions; selective pressure; emerging infectious diseases

\section{Introduction}

The emergence and dissemination of antimicrobial resistance among human, animal, and zoonotic pathogens poses an enormous threat to people around the world [1,2]. According to a report from the World Health Organization [3], the magnitude of antimicrobial resistance in many parts of the world has reached alarming levels and clearly suggests that a 'post antibiotic era' may be a real possibility for the 21st century. The importance of this growing problem can be illustrated by the emergence of plasmid-mediated colistin resistance among human, animal and zoonotic pathogens, for example. Prior to the emergence of plasmid mediated colistin resistance, carbapenem-resistant Enterobacteriaceae that express enzymes such as KPC-2 (Klebsiella pneumoniae carbapenemase-2) and NDM-1 (New Delhi metallo- $\beta$-lactamase- 1 ) already generated serious concerns around the world due to their multidrug-resistant phenotype and subsequently limited options for treatment [4]. The treatment options of any life-threatening infection caused by carbapenemase-producing Enterobacteriaceae would be severely limited, relying on only two antibiotics, tigecycline and colistin [5]. Colistin or polymixin $\mathrm{E}$ is a potent polycationic polypeptide that possesses both hydrophilic and lipophilic properties [6], which can effectively disorganize the outer membrane of a wide spectrum of Gram-negative bacteria. 
Until recently, only chromosomally mediated resistance to colistin was observed [7]. However, in 2016 the first plasmid-mediated colistin resistance was reported among several species of the Enterobacteriaceae family [8]. The authors of this report found a plasmid carrying the $m c r-1$ gene that encodes MCR-1 enzyme, of the phosphoethanolamine transferase enzyme family, which provides modification of the outer membrane and colistin resistance to bacteria that harbor this plasmid. More specifically, the expression of the $m c r-1$ gene leads to the addition of phosphoethanolamine to lipid A, which results in the reduction of affinity between colistin and lipopolysaccharides of Gram-negative bacteria. The authors of this report also observed that the plasmid carrying the mcr-1 gene is transmissible between several Gram-negative species including Escherichia coli, Klebsiella pneumoniae, and Pseudomonas aeruginosa [8]. This finding clearly indicates a likely possibility for the horizontal spread of colistin resistance to different species of Enterobacteriaceae and other Gram-negative species as well. Indeed, within several years of this report, the presence of the $m c r-1$ gene or its variants (e.g., from $m c r-2$ to $m c r-8$ ) and subsequent colistin resistance have been detected in numerous bacterial species originating from animals, humans and environments around the world [9-12].

Besides the use of colistin for human treatments, this antibiotic has been heavily used in veterinary practice, especially as an additive in feed for promoting growth of food animals in many parts of the world [13]. It has been hypothesized that the industrial-scale incorporation of colistin as a growth promoter for food animals has had a significant contribution to the emergence of colistin resistance [8]. This hypothesis is further supported by the fact that initially a high prevalence of the $m c r-1$ genes was found among colistin-resistant isolates originating from animals compared to a small prevalence of the colistin resistant isolates originating from humans [8]. Examples of the emergence and spread of colistin resistance suggests that research studies designed to investigate the impact of livestock practices on the emergence of antibiotic resistance in the livestock settings and their transfer to the environment are urgently needed. This review article summarizes and presents the relevant and recent findings in the area of antimicrobial resistance and livestock production.

\section{Mechanism of Antibiotic Resistance Development}

Development of antibiotic resistance occurs via two major pathways; (i) vertically through de novo mutations and (ii) horizontally via the introduction of antibiotic resistance genes.

\subsection{Vertical Acquisition of Antimocrobial Resistance}

Once a population of bacteria is exposed to lethal, sublethal or even low concentrations of antibiotic, a selective pressure starts to act on the bacterial population [14]. Any mutation that will provide a full or partial resistance to a particular antibiotic will be preserved and vertically transmitted to progeny cells, further providing a survival or growth advantage (i.e., it depends on antibiotic concentration) to mutated cells compared to that of non-mutated (i.e., parental) cells. De novo mutations may generate bacterial resistance to a specific antibiotic exclusively, or to a class of antibiotics, when target-site gene mutation/s occur for that specific antibiotic. An example of de novo mutations that exclusively generate a resistance to a specific antibiotic or class of antibiotics can be found among fluoroquinolone-resistant isolates. The fluoroquinolones, a potent, broad-spectrum class of antibiotics, target bacterial type II topoisomerases, primarily DNA gyrase (GyrA and GyrB) in Gram-negative and DNA topoisomerase IV (ParC and ParE) in Gram-positive bacteria. This drug binds the GyrA or ParC enzymes at their substrate (i.e., DNA) target site $[15,16]$, resulting in dysfunctional topoisomerase II enzymes, which are able to cleave chromosomal DNA, but unable to re-ligate the chromosome [17]. This interaction of the drug and bacterial type II topoisomerases causes a fragmentation of chromosomal DNA, which subsequently leads to cellular death $[18,19]$. Non-synonymous mutations that arise in the gyrA and parC genes, specifically in a short DNA region known as the quinolone resistance-determining region (QRDR), alter the substrate structure (i.e., DNA) of the GyrA or ParC [20]. These target-site amino acid substitutions lead to a reduced binding affinity of fluoroquinolone to mutated GyrA and ParC enzymes [21], further providing an exclusive resistance to fluoroquinolone class of antibiotics. 
Besides mutations that provide exclusive resistance to a specific antibiotic or class of antibiotics, most commonly, de novo mutations generate resistance to a diverse group of functionally unrelated antibiotics. Mutations that cause the overexpression of genes encoding efflux-pump proteins usually lead to the development of multidrug resistance (MDR) [22-24] in bacteria. For instance, the AcrAB-TolC, a member of the resistance-nodulation division (RND) family of efflux pumps, may provide MDR to Gram-negative bacteria via de novo mutations that occur in the promoter region of the AcrAB [25], mutations that occur in regulators of the AcrAB efflux pump marA [26], soxS [27], rob [28], and acrR [29] as well as mutations that affect the repressor $\operatorname{ramR}[24,30]$ of the AcrAB efflux. Efflux-pump associated mutations can not only lead to the development of MDR, but they can also cause a significant alteration in antibiotic susceptibility, developing a resistance to certain classes of antibiotics while conferring increased susceptibility to other classes of antibiotics [23]. It has been shown that de novo mutations simultaneously cause the overexpression of MDR pumps and significant down regulation of the major porins $\mathrm{OmpF}$ and OmpC [24], consequently leading to a reduced influx and an increased efflux of a mutated bacterial cell. In addition, decrease of porin-mediated permeability may occur during extracytoplasmic stress, via the $\sigma^{\mathrm{E}}$ regulatory loop [31], which upregulates small regulatory RNAs, MicA, RybB, and MicL that consequently antagonize synthesis of outer membrane proteins [32-34].

One of the adaptive strategies employed by prokaryotes during antimicrobial treatment is the development of the small colony variant (SCV), a phenotype characterized by a slow growth rate. It has been shown that the SCV-conferring mutations occur in a part of the genome that affects the electron transport and thymidine biosynthesis of bacteria [35-39], ultimately compromising ATP production and the electrochemical gradient across the cytoplasmic membrane [40,41]. These studies showed that the electron-transport and thymidine-biosynthesis defective SCVs mutants could be reversed to a normal (i.e., wild type) phenotype by supplementation with growth factors (i.e., menadione, hemin, and thymidine). The reversion of the SCV to a wild type phenotype by supplementation with growth factors clearly illustrates the auxotrophic nature of these SCV mutants. The acquisition of the SCV phenotype by pathogenic bacteria can have profound clinical consequences for an infected patient. The slow growth rate renders antibiotics less effective [35], promoting enhanced antimicrobial resistance among SCV bacteria, which often results in recurrent infections [42,43]. In recent years, it has become clear that SCVs play an important role in the development of chronic and antibiotic resistant infections, further contributing to an increased mortality rate of patients affected by infectious diseases [44].

\subsection{Horizontal Acquisition of Antimocrobial Resistance}

Unlike vertically acquired antimicrobial resistance, horizontal acquisition of antimicrobial resistance occurs via horizontal transfer (e.g., conjugation, transformation and transduction) of mobile antibiotic resistant genetic elements from a donor to a recipient bacterial cell. Plasmids and conjugative transposons (i.e., a small region of bacterial chromosome that encodes enzymes for its translocation) are common and important vehicles for intra and inter species or genera [45] dissemination of antimicrobial resistance. The origins of antimicrobial resistant genes are commonly identified among different environmental bacterial genera including Kluyvera [46], Shewanella [47], and Vibrionaceae [48]. It has been hypothesized that the potential origin of the bla $a_{\mathrm{CTX}-\mathrm{M}}$ genes, the most prevalent cause of extended-spectrum $\beta$-lactamases (ESBLs) in Enterobacteriaceae worldwide, was the chromosomal DNA of environmental Kluyvera genus [46]. It is believed that more recently the OXA-48-type carbapenem-hydrolyzing $\beta$-lactamase genes, found in Enterobacteriaceae, originated from the chromosome of waterborne, environmental Shewanella genus [47]. As illustrated by these two examples, the horizontal acquisition of antimicrobial resistance provides an effective transfer of antimicrobial resistance traits from different ecological niches to the clinically relevant species that subsequently can result in the emergence of not only multidrug resistant strains, but even pan-drug resistant strains.

Another effective vehicle for horizontal transfer of antimicrobial resistance between various bacterial species, specifically between Gram-negative bacteria, are various types of integrons [49]. 
These genetic elements are gene acquisition platforms that contain three genetic features necessary for the proper function of any integron, (i) intl gene that encodes an integron integrase, (ii) an integron-associated recombination site, attl, and (iii) an integron-associated promoter, Pc [50]. According to the literature, there are five classes of integrons that confer resistance to clinically relevant antibiotics [49]. The class 1 integrons are the most commonly found among clinical isolates, while classes 2 and 3 are also recovered from clinical isolates, albeit at lower frequencies compared to that for the class 1 integrons [49]. Another two classes of integrons, class 4 integrons are recovered from the human pathogen, Vibrio cholera, while class 5 integrons are found on the pRSV1 plasmid originated from Alivibrio salmonicida [49]. It has been estimated that these integrons carry about 130 different resistance gene cassettes, whose phylogeny and vast diversity indicate that these antibiotic resistance genes have been periodically captured from various genetic backgrounds [51]. It is believed that integrons play a major role in the spread of antibiotic resistance worldwide [49]. Driven by strong selective pressure, it can be expected to see an emergence and spread of integrons that confer resistance to different classes of antibiotics, antiseptics, and other harsh chemicals.

\section{Antimicrobial Resistance Associated with Food Producing Animals}

The use of antibiotics in human medicine, veterinary medicine, and agriculture has been correlated to the emergence and spread of antibiotic resistance worldwide. Especially, the use of antibiotics at industrial scale for growth promotion of food animals is believed to be a major contributor to the trend of the emergence and spread of bacteria with antibiotic resistant traits. Initially, a connection between an increase of multidrug resistance and the use of antibiotics as growth promoters was first recognized in the United Kingdom during the 1960s. This recognition was presented by the Swann Commission, which further recommended that antibiotics of human relevance should be banned for use as growth promoters for food-animals [52]. The European Union in 1999 made a step forward in the regulation of use of antibiotics in the agriculture industry by prohibiting the use of four classes of antibiotics as growth promoters, followed in 2006 by banning all growth promotion classes of antibiotics in food-producing animals [53]. The implementation of these regulations sparked debates whether the new measures designed to significantly reduce use of antibiotics in food-producing animals will have any effect on the emergence and spread of antibiotic resistance, particularly in the human population. Tang and collages [54] carried out a first systematic review followed by meta-analysis to determine the associations between measures that prohibited or reduced use of antibiotics in the food-producing animals and occurrence of antibiotic resistance in humans and animals. This research group searched numerous electronic databases and grey literature for studies that aimed to determine a relationship between any measures designed to reduce antibiotic use in food-producing animals and occurrence of antibiotic resistance in humans and animals. Based on 179 and 21 studies that described antibiotic resistance outcomes in animals and humans, respectively, this research group found a positive correlation between reducing antibiotic use in food-producing animals and the occurrence of antibiotic resistance in the studied animals. They also observed a similar correlation between reduced antibiotic use in food-animals and reduced prevalence of antibiotic resistance in humans, specifically in humans that had a direct contact with food-producing animals. A similar study carried out by Scott et al. [55], where the authors analyzed 93 studies using different animal species, antimicrobial classes, interventions, administration routes, samples and methods, showed that limiting antimicrobial use in food-animals subsequently reduces antimicrobial resistance in food-animals. These two systematic reviews, analyzing the large body of literature, undoubtedly showed that interventions designed to reduce use of antibiotics in food-producing animals indeed have a positive effect on reducing the prevalence of antibiotic resistance in both animals and humans that are in contact with food-producing animals. The implications of these measures for the general public are less certain, as a limited number of studies associated with this particular topic could be examined.

Besides this major correlation between the prohibition or reduction of antibiotic use as growth promoters and occurrence of antibiotic resistance in food-producing animals, there is another important 
fact to be considered during implementation of such measures (e.g., restrictions of antibiotic use in agriculture). Obviously, any implementation of measures designed to reduce use of antibiotics in food-producing animals will have multiple consequences. These measures will not only cause changes in the prevalence of antibiotic resistance but also, they will subsequently influence animal health and cost of production. McEwen et al. [56] undertook a keyword search using publicly available databases, MEDLINE and AGRICOLA, for studies that reported unintended consequences associated with national-level restrictions on antimicrobial use in food-producing animals. The search resulted in a limited number of studies (e.g., 14), exclusively from Europe. After implementation of antibiotic growth promotions (AGPs) ban in Sweden and Denmark there were initial increases of diarrhea in weanling pigs, while in other food-animal species be there was minor or no diarrhea increase observed $[57,58]$. It was found that in both countries, these initial problems with diarrhea incidents were successfully resolved, mainly by improving animal housing, hygiene and health management $[57,58]$. Similar observations were made in Norway [59] and the Netherlands [60], where initially there were reported increases in antibiotic use for the treatment or prevention of infectious disease. However, these increases in antibiotic use for infection treatment of food-animals were reduced to the previous level, prior to implementation of AGPs bans, exclusively by improvements in housing, hygiene and health managements. Although these studies came from a geographically confined area (e.g., Western Europe), the available data suggests that an increase in diarrhea incidence can be expected after an AGP ban, especially in weanling pigs. However, these initial problems are of transient nature, which do not possess any significant risk for the animals' health and/or cost of production. Mainly through improvements in animal housing, hygiene, and health management can these problems be resolved.

\section{Zoonotic Transmission of Antimicrobial Resistance to Humans}

Transmission routes of antimicrobial resistant bacteria to humans are often extremely complex and hard to predict. In general, there are two major routes; i) direct acquisition of antimicrobial resistance through contact with the food-producing animals or human carriers and ii) indirect acquisition of antimicrobial resistance through the food chain or via exposure to niches of high antimicrobial resistance pollution (e.g., hospitals, nosocomial acquisition, manure, waste water and agriculture land).

Numerous studies, examining the transmission of antimicrobial resistant bacteria from animal to humans, reported the high prevalence rate of antimicrobial resistant bacteria among individuals that have a direct contact with animals, specifically farm workers [61,62] and veterinarians [63]. Among the first authors, Levy and colleagues [64] reported a direct transmission of multidrug resistant $E$. coli from animals to animals and also from animals to humans. This research group used E. coli strains that harbored R plasmid which expressed resistance to multiple families of antibiotics including chloramphenicol, tetracycline, sulphonamides and streptomycin. Once, multidrug resistant E. coli strains were introduced into the intestine of four chickens, and each infected chicken was caged with 50 uninfected chickens. In addition, two groups of chickens were fed on a tetracycline-supplemented feed, whereas another two groups of chickens were fed on antibiotic free feed. The authors of this study found the multidrug resistant $E$. coli strain with the test $\mathrm{R}$ plasmid only in chickens that were fed on a tetracycline-supplemented feed. Interestingly, over the duration of this experiment (e.g., a two-month period), R plasmid was detected in the fecal samples of human individuals that worked or lived on this particular farm. The authors of this study clearly demonstrated the importance of the zoonotic transmission route in acquisition of antimicrobial resistant bacteria. This study also highlighted the importance of the use of antibiotics as growth promoters in the spread of multidrug resistant phenotypes. Besides the existence of selective pressure, the high densities of food-producing animals, living in close quarters to one another, may also significantly contribute to the dissemination of antimicrobial resistant bacteria. A research group [65] that examined the ecology of enterohemorrhagic E. coli in numerous feedlot operations observed a statistically significant $(p=0.003)$ positive correlation between the density of cattle and the prevalence rate of this zoonotic pathogen. Taken together, it can be assumed that the use of antibiotics in agriculture, specifically the massive use of antibiotics for 
growth promotion, can lead to the emergence of antibiotic resistant bacteria. Once antibiotic resistant bacteria emerged among the food-producing animals, this phenotypic trait will be preserved by the same selective pressure and quickly spread to other animals and humans due to the high conductivity of such environments (e.g., high animal densities in the confide areas [feedlots and barns]).

Indirect acquisition of antimicrobial resistant bacteria is usually more complex compared to direct acquisition. It is known that a considerable amount of antibiotics used in agriculture, human and animal medicine reaches the environment in their active forms [66]. Subsequently, the presence of active antibiotic compounds in the environment imposes a selective pressure that may result in the emergence of antibiotic resistant phenotypes among various microbial species that naturally occupy this niche. If the antibiotic resistance phenotype emerges on a mobile genetic element, it can be horizontally transmitted to human, animal or zoonotic pathogens, which may pose a considerable public health threat. This environmental transmission route has been well documented. For instance,

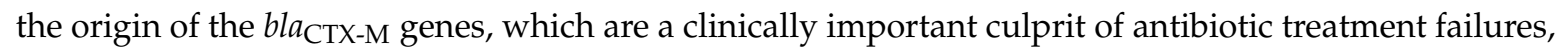
emerged from environmental Gram-negative bacteria Kluyvera spp. [46]. Also, the OXA-48-type carbapenem-hydrolyzing $\beta$-lactamase genes, an important cause of antimicrobial treatment failures as well, originated from the marine bacteria family Shewanellaceae [47].

Aerosols generated from areas of high antimicrobial resistance pollution represent another important vehicle that can indirectly transmit antimicrobial resistant bacteria to humans, animals and the environment in general. Madsen et al. [67] examining the presence of airborne methicillin-resistant Staphylococcus aureus (MRSA) in four pig farms, found the geometric mean concentrations of MRSA and $S$. aureus to be 447 colony forming units (CFU)/m3 air and $1.8 \times 10^{3} \mathrm{CFU} / \mathrm{m} 3$ air, respectively. A great majority of MRSA and S. aureus were associated with particles between 7 and $12 \mu \mathrm{m}$ in size, which can be deposited in the human upper airways, the primary, secondary and terminal bronchi and the alveoli. Interestingly, a great majority of the zoonotic transmission of MRSA isolates to humans in Europe and North America belongs to clonal complex (CC) 398, whereas CC 9 is the major livestock associated (LA)-MRSA clone in Asia [68]. For instance, a Dutch-German research group that studied a large number $(n=14,036)$ of MRSA isolates from clinical specimens of human origin in a German region characterized by a high density of livestock production, found that $18.6 \%$ of all human isolates associated with LA-MRSA CC398 based on livestock-indicator (LI) S. aureus protein A (spa) types [69]. Based on the same LI spa typing the authors of this study identified another four LA CCs among human MRSA isolates including, CC9 (0.14\%), CC97 (0.01\%), CC5 (1.01\%) and CC30 (0.04\%), indicating that CC398 is predominant among LA-MRSA in this region of Europe. In Denmark, Harrison et al. [70] using whole genome sequencing identified zoonotic transmission of novel mecC-MRSA ST130 between livestock and humans, indicating that LA-MRSA is highly adaptable and most likely constantly evolving. A research group from China [71], examining the effect of swine, cattle, layer and broiler farms on the spread of airborne antibiotic resistant bacteria, found that animal species are a detrimental factor in shaping total culturable and antibiotic resistant bacterial airborne communities. The importance of livestock environment on the emergence and dissemination of antimicrobial resistant phenotypes was reported by An et al. [72]. Using a well-defined population of non-typhoidal Salmonella (NTS) isolates associated with avian, bovine and porcine hosts, this research group found that the livestock environment had a specific $(p<0.005)$ and profound $(p<0.005)$ effect on the evolution of multidrug-resistant phenotypes among population of NTS isolates.

However, there are numerous studies that found no transmission link between zoonotic pathogens of animal and human origins. For instance, Mather et al. [73], using whole-genome sequences of a national collection of non-typhoidal Salmonella isolates of human and animal origins, as well as international derived isolates originated from humans and animals, found that the bacterium and its resistance genes were mainly kept within their host origins with limited transmission. Another group of authors, comparing over 430 isolates of E. coli (including 155 ESBL-producing isolates) isolated from livestock and retail meat with the genomes of 1,517 E. coli isolates associated with blood stream infections from the United Kingdom, found that these two groups of E. coli were genetically distinct 
populations [74]. They observed only a limited overlap in the mobile elements carrying AMR from livestock-associated and bloodstream isolates. Regarding transmission links of zoonotic pathogens and their AMR between livestock and humans, current data shows be conflicting findings and controversy, indicating that these processes are extremely complicated.

\section{Novel Approaches Designed to Prevent or Slow Down the Emergence of Antimicrobial Resistance}

There is a great need for developing alternative approaches to more effectively control the emergence and spread of antimicrobial resistance, in particular, the resistance to clinical antibiotics used in human therapy.

Over the last decade in the domain of antimicrobial research, engineered metal nanoparticles (NPs) have attracted a global attention due to their high and long-lasting microbial toxicity [75-77]. The antimicrobial properties of NPs are based on their high surface area-to-volume ratio, which tremendously increases the reactivity of NPs, subsequently leading to a high production of reactive oxygen species (ROS) and free metal ions. Certain metal NPs show high and broad-spectrum antimicrobial activities [78] as well as no toxicity to humans [79]. To fully exploit such properties of metal NPs, an advanced technological approach in the formulation and application of metal NPs is required. The published work of Malka and colleagues [80] showed great promise in the application of zinc-doped CuO NPs against MDR bacteria. The authors synthesized zinc-doped copper oxide NPs and subsequently deposited them on cotton fabric using ultrasound irradiation techniques. This in situ coating process resulted in the creation of cotton fabric with profound antimicrobial activity. A reduction of up to six logs after a 10-minute treatment was observed for both antimicrobial susceptible and MDR-strains of E. coli and $S$. aureus, clearly showing the outstanding antimicrobial potency of the novel Zn-doped CuO NPs against MDR strains.

The lethal effect of these novel $\mathrm{Zn}-\mathrm{CuO}$ NPs is achieved by a high production of $\mathrm{OH}$ radicals, superoxide anions $\left(\mathrm{O}_{2}^{-}\right)$, molecular oxygen $\left(\mathrm{O}_{2}\right)$, and most likely $\mathrm{Zn}^{2+}$ (Figure 1).

Once the $\mathrm{Zn}-\mathrm{CuONPs}$ were immobilized on the cotton, the antimicrobial activity of the coated fabric was stable for at least six months, denoting that the novel material has a long-lasting antimicrobial effect. Besides the use of NPs for creation of surfaces with antimicrobial properties, NPs found a promising application in conjugation with existing antibiotics. Recently, Kooti and colleagues [81] demonstrated that the antimicrobial activity of ciprofloxacin conjugated to a NP composite (e.g., graphene oxide, cobalt ferrite and silver NPs) is greatly enhanced compared to that of either NPs or ciprofloxacin alone. The authors of this study also found that this multifunctional composite could potentially be used as a drug-delivery system, mainly due its ability to gradually release drug over an extended period of time.

The use of bacteriophages has recently gained great interest, mostly due to the emergence and spread of antimicrobial resistance [82]. Bacteriophages are viruses that use bacterial cells for propagation. Only bacteriophages that undergo the lytic cycle can be used against human, animal or zoonotic pathogens, both susceptible and resistant to various antibiotics. Presently, there are two commercial Listeria phage products, ListShieldTM and ListexTM P100 [83] approved as food preservatives. There are several studies that tested the efficacy of this new product against Listeria monocytogenes. Soni and Nannapaneni [84] observed a 5-log reduction of L. monocytogenes after a $24 \mathrm{~h}$ treatment at room temperature with ListexTM P100. This product was tested also against already developed biofilms of L. monocytogenes and Iacumin et al. [85] observed a complete dissolution of L. monocytogenes biofilm on stainless steel wafers after applying ListexTM P100 for $24 \mathrm{~h}$ at $20{ }^{\circ} \mathrm{C}$. Another group of authors that used a shorter treatment time (e.g., two hours), observed only a 2-log reduction of L. monocytogenes biofilm on stainless steel [86]. Another research group [87] tested reduction of L. monocyogenes from the surface of fresh channel catfish fillets by bacteriophage ListexTM P100. They found that the phage contact time of $30 \mathrm{~min}$. was adequate to yield a greater than $1 \log 10$ reduction in L. monocytogenes, whereas $15 \mathrm{~min}$. contact time resulted in less than $1 \log 10 \mathrm{CFU} / \mathrm{g}$ reduction in L. monocytogenes counts on the surface of catfish fillets. Further studies designed to test the efficacy of bacteriophage treatments 
against various pathogens under different conditions will reveal the true potential of this promising biological intervention technology against the emergence and dissemination of antimicrobial resistant phenotypes as well as human and zoonotic pathogens.

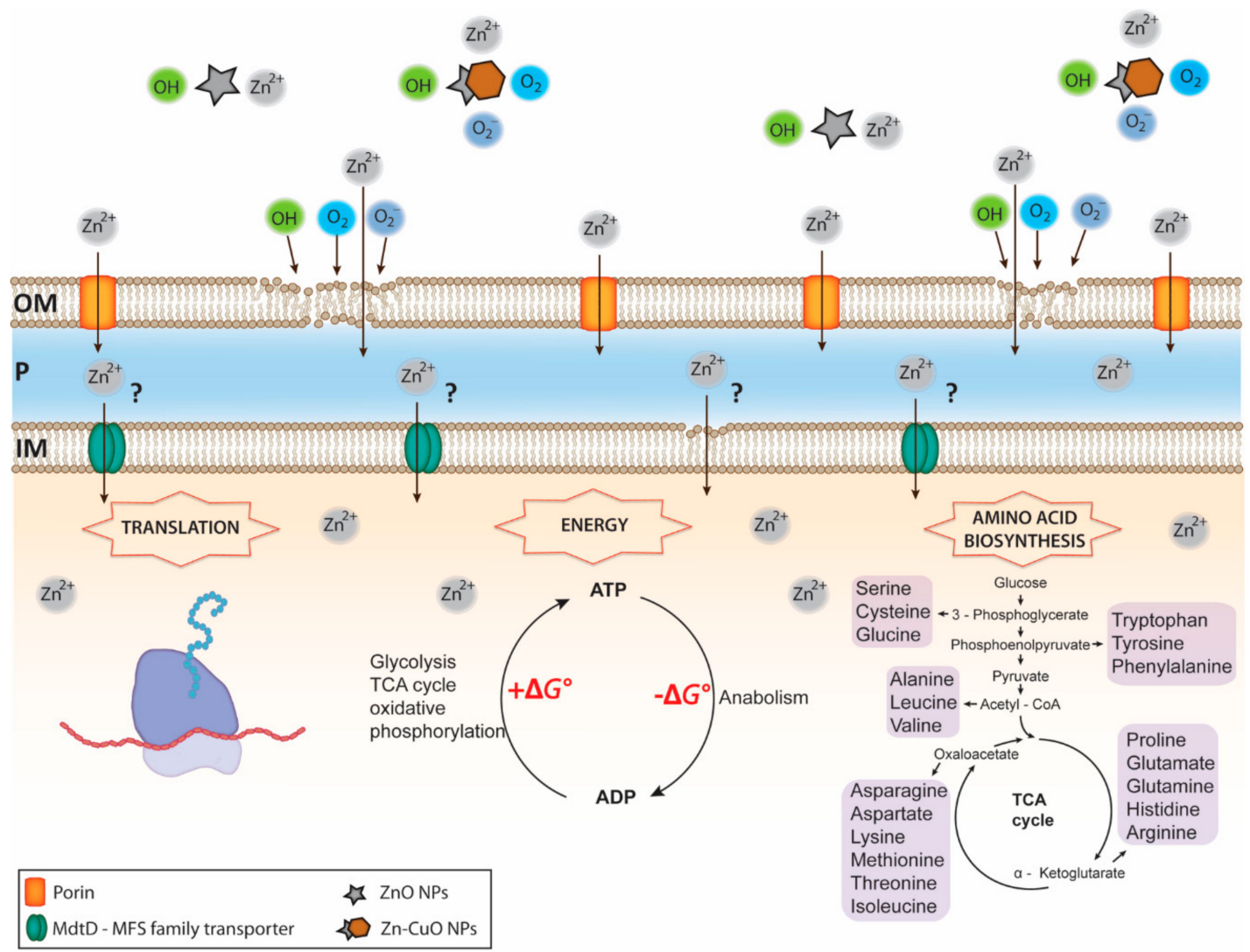

Figure 1. Overview of Zn NPs mediated toxicity against a Gram-negative organism. ZnO and ZN-CuO NPs release high concentrations of reactive oxygen species (ROS) and $\mathrm{Zn}^{2+}$, followed by $\mathrm{Zn}^{2+}$ entrance into the periplasmic space via porins and the outer membrane lipid peroxidation caused by ROS (i.e., $\mathrm{OH}, \mathrm{O}_{2}$, and $\mathrm{O}_{2}{ }^{-}$). The process of lipid peroxidation leads to an increase the outer membrane permeability, resulting in an enhanced influx of $\mathrm{Zn}^{2+}$ into the periplasm milieu. Transport of highly concentrated $\mathrm{Zn}^{2+}$ across the inner membrane remains largely unknown. It can be hypothesized that $\mathrm{Zn}^{2+}$ enters the cytoplasm through a permeabilized inner membrane, caused by an ongoing process of lipid peroxidation and also via MFS transporters, as they can facilitate symport, antiport and uniport transfer in response to chemiosmotic ion gradients. Once penetrated, the intracellular $\mathrm{Zn}^{2+}$ reacts with a wide range of proteins leading to down-regulation and inhibition of enzymes and proteins involved in translation, the ATP cycle and the amino acid biosynthesis, all key metabolic processes. Disruption of these central metabolic processes leads to serious metabolic imbalances and finally to cellular death. OM, outer membrane; P, periplasmic space; IM, inner membrane.

Another antibiotic alternative is the potential use of bacteriocins, a group ribosomal synthesized peptides or proteins that show antimicrobial properties [88]. Over the last decade bacteriocins have attracted considerable attention in the area of antimicrobial research due to their distinct mode of actions. Depending on the class of bacteriocins, these antimicrobial peptides or proteins may have a bactericidal effect (e.g., causing cell death) or a bacteriostatic effect (e.g., inhibiting cell growth). Some classes of bacteriocins inhibit peptidoglycan synthesis by targeting lipid II, an integrative molecule of bacterial cell envelope [89]. Other classes of bacteriocins have binding affinity for lipid II and once attached to it they form a pore into bacterial cell envelope, further causing loss of cellular turgor, disruption of electrochemical gradient and finally, cell death [90]. Besides targeting the bacterial 
cell wall envelope, different classes of bacteriocins may inhibit central metabolic processes including gene expression, DNA replication, and protein synthesis [91]. Although numerous bacterial species can produce bacteriocins, most of the attention has been directed towards the lactic acid bacteria (LAB) as they are prolific producers of these antimicrobial peptides. Gomez et al. [92] examined three LAB species, Lactococcus lactis, Lactobacillus sakei, and Lactobacillus curvatus, against biofilms of major foodborne pathogens, L. monocytogenes, E. coli O157:H7 and S. enterica serovar Typhimurium. This research group observed a complete inactivation of biofilms over a 72-hour period using L. sakei and L. curvatus, while L. lactis caused a 6-log reduction over the same period of time. Another research group [93] used nisin, a bacteriocin approved for commercial use, against biofilm of L. monocytogenes over a 9-hour period and they observed a $3.5 \mathrm{log}$ reduction during $48 \mathrm{~h}$. There is a great diversity among bacteriocins. Alverz-Sieiro et al. [94] reported that over 230 different bacteriocins have been found to be produced by LAB. Only a small portion of these promising antimicrobial peptides have been tested.

Besides the above-mentioned alternatives, using multiple antibiotics to exploit collateral sensitivity of otherwise antibiotic resistant bacteria has shown promising results. Harrison et al. [95] showed that a significant proportion of MRSA isolates including, the epidemic USA300 lineage, can be reverted to penicillin susceptibility when used in combination with clavulanic acid, a $\beta$-lactamase inhibitor. The authors of this study concluded that although combination of penicillins and $\beta$-lactamase inhibitors most likely will not be used as a monotherapy, it can be an alternative therapeutic option for hard-to-threat infections.

\section{Conclusions and Future Perspectives}

The challenges with the emergence and spread of antibiotic resistance associated with the use of antibiotics in livestock are very complex and have multifaceted effects not only on animals, but on humans and the environment as well. It becomes clear that the use of antibiotics in livestock requires a global response, so that the measures undertaken to control the emergence and spread of antimicrobial resistance have a satisfactory effect. The first observations from countries that have already implemented bans for antibiotic use in livestock, particularly bans for growth promotion, indicate that these measures are not only sustainable, but they are profitable too. After an initial increase of diarrhea incidence, mainly in weanling pigs, improvement in animal housing, hygiene and health management resulted in reduced diarrhea incidence compared to previous levels, prior to the implementation of AGPs bans. Importantly, the recent estimates indicate that between 2010 and 2030, the global consumption of antimicrobials will increase by $67 \%$, from $63,151 \pm 1,560$ tons to 105,596 tons [96]. It is believed that one third of this global increase will be related to shifting production practices in the livestock industries of middle-income countries [96]. Indeed, the most recent report, where a group of authors analyzed 901 point prevalence surveys in developing countries looking at antimicrobial resistance of pathogens isolated from animals, revealed that China and India represent the largest hotspots of resistance, with new hotspots emerging in Brazil and Kenya [97]. The same group of authors proposed that high-income countries, where antimicrobials have been used on farms since the 1950s, should support the transition to sustainable animal production in low- and middle-income countries [97]. To globally implement the WHO Global Action Plan together with the Food and Agriculture Organization (FAO) recommendations regarding the AGPs ban, it would be of a crucial importance to provide technical and financial support to developing countries, so that the entire human society can benefit fully by an AGPs ban.

Through further education of the public and professionals regarding the effects of unnecessary antibiotic use in human and veterinary medicine as well as in livestock on the emergence and spread of antibiotic resistance, it can be anticipated that the use of antibiotics will be more restricted in the future. Besides the implementation of restrictive measures for antibiotic use, it can be expected that future technological developments will significantly improve delivery and efficacy of clinical antibiotics against infectious diseases both in humans and animals. It can be assumed that the technological 
advances will not only improve the efficacy of the existing antibiotics, but also, they could potentially find suitable alternatives for certain types of antibiotic treatments. In the fight against the emergence and spread of antibiotic resistance, it is of crucial importance that the measures proposed by the WHO are implemented on a global scale.

Author Contributions: Conceptualization S.V. and N.V.; writing N.V. and S.V. All authors have read and agreed to the published version of the manuscript.

Funding: This work was supported by the United States Department of Agriculture, National Institute of Food and Agriculture, Hatch Capacity Grant \# 592 and the Signature Program AES GAR grant (University of Minnesota).

Acknowledgments: The authors gratefully acknowledge the technical support from Daniela Vidovic.

Conflicts of Interest: The authors declare no conflict of interest.

\section{References}

1. Wittum, T.E.; Mollenkopf, D.F.; Erdman, M.M. Detection of Salmonella enterica producing CTX-M cephalosporinase in US livestock populations. Appl. Environ. Microbiol. 2012, 78, 7487-7491. [CrossRef] [PubMed]

2. Espadinha, D.; Faria, N.A.; Miragaia, M.; Lito, L.M.; Melo-Cristino, J.; Lencasstre, H. Médicos Sentinela Network. Extensive dissemination of methicillin-resistant Staphylococcus aureus (MRSA) between the hospital and the community in a country with a high prevalence of nosocomial MRSA. PLoS ONE 2013, 8, e59960. [CrossRef] [PubMed]

3. World Health Organization. Antimicrobial Resistance: Global Report on Surveillance; World Health Organization: Geneva, Switzerland, 2014.

4. Falagas, M.E.; Karageorgopoulos, D.E.; Nordmann, P. Therapeutic options for infections with Enterobacteriacaea producing carbapenem-hydrolyzing enzymes. Future Microbiol. 2011, 6, 653-666. [CrossRef] [PubMed]

5. Tzouvelekis, L.S.; Markogiannakis, A.; Piperaki, E.; Souli, M.; Daikos, G.L. Treating infections caused by carbapenemase-producing Enterobacteriacaea. Clin. Microbiol. Infect. 2014, 20, 862-872. [CrossRef]

6. Li, J.; Nation, R.L.; Turnidge, J.D.; Milne, R.W.; Coulthard, K.; Rayner, C.R.; Paterson, D.L. Colistin: The re-emerging antibiotic for multidrug-resistant Gram-negative bacterial infections. Lancet Infect. Dis. 2006, 6, 589-601. [CrossRef]

7. Cheng, H.Y.; Chen, Y.F.; Peng, H.L. Molecular characterization of the PhoPQ-PmrD-PmrAB mediated pathway regulating polymyxin B resistance in Klebsiella pneumoniae CG43. J. Biomed. Sci. 2010, 17, 60. [CrossRef]

8. Liu, Y.Y.; Wang, Y.; Walsh, T.R.; Yi, L.X.; Zhang, R.; Spencer, J.; Doi, Y.; Tian, G.; Dong, B.; Huang, X.; et al. Emergence of plasmid-mediated colistin resistance mechanism MCR-1 in animals and human beings in China: A microbiological and molecular biological study. Lancet Infect. Dis. 2016, 16, 161-168. [CrossRef]

9. Monte, D.F.; Mem, A.; Fernandes, M.R.; Cerdeira, L.; Esposito, F.; Galvao, J.A.; Franco, B.D.G.M.; Lincopan, N.; Landgraf, M. Chicken meat as a reservoir of colistin-resistant Escherichia coli strains carrying mcr-1 genes in South America. Antimicrob. Agents Chemother. 2017, 61, e02718-16. [CrossRef]

10. Brauer, A.; Telling, K.; Laht, M.; Kalmus, P.; Lutsar, I.; Remm, M.; Kisand, V.; Tenson, T. Plasmid with colistin resistance gene $m c r-1$ in extended-spectrum- $\beta$-lactamase-producing Escherichia coli strains isolated from pig slurry in Estonia. Antimicrob. Agents Chemother. 2016, 60, 6933-6936. [CrossRef]

11. Chiou, C.S.; Chen, Y.T.; Wang, Y.W.; Liu, Y.Y.; Kuo, H.C.; Tu, Y.H.; Lin, A.C.; Liao, Y.S.; Hong, Y.P. Dissemination of $m c r$-1-carrying plasmids among colistin-resistant Salmonella strains from humans and food-producing animals, Taiwan. Antimicrob. Agents Chemother. 2017, 61, e00338-17. [CrossRef]

12. Coetzee, J.; Corcoran, C.; Prentice, E.; Moodley, M.; Mendelson, M.; Poirel, L.; Nordmann, P.; Brink, A.J. Emergence of plasmid-mediated colistin resistance (MCR-1) among Escherichia coli isolated from South African patients. S. Afr. Med. J. 2016, 106, 449-450. [CrossRef] [PubMed]

13. Wertheim, H.; Nguyen, K.V.; Hara, G.L.; Gelband, H.; Laxminarayan, R.; Mouton, J.; Cars, O. Global survey of polymyxin use: A call for international guidelines. J. Glob. Antimicrob. Resist. 2013, 1, 131-134. [CrossRef] [PubMed]

14. Kruse, H.; Sorum, H. Transfer of multiple drug resistance plasmids between bacteria of diverse origins in natural microenvironments. Appl. Environ. Microbiol. 1994, 60, 4015-4021. [CrossRef] [PubMed] 
15. Laponogov, I.; Sohi, M.K.; Veselkov, D.A.; Pan, X.S.; Sawhney, R.; Thompson, A.W.; McAuley, K.E.; Fisher, L.M.; Sanderson, M.R. Structural insight into the quinolone-DNA cleavage complex of type IIA topoisomerases. Nat. Struct. Mol. Biol. 2009, 16, 667-669. [CrossRef] [PubMed]

16. Laponogov, I.; Veselkov, D.A.; Crevel, I.M.; Pan, X.S.; Fisher, L.M.; Sanderson, M.R. Structure of an 'open' clamp type II topoisomerases-DNA complex provides a mechanisms for DNA capture and transport. Nucleic Acids Res. 2013, 41, 9911-9923. [CrossRef]

17. Redgrave, L.S.; Sutton, S.B.; Webber, M.A.; Piddock, L.J.V. Fluoroquinolone resistance: Mechanisms, impact on bacteria, and role in evolutionary success. Trends Microbiol. 2014, 22, 438-445. [CrossRef]

18. Walters, R.N.; Piddock, L.J.; Wise, R. The effect of mutations in the SOS response on the kinetics of quinolone killing. J. Antimicrob. Chemother. 1989, 24, 863-873. [CrossRef]

19. Drlica, K.; Hiasa, H.; Kerns, R.; Malik, M.; Mustaev, A.; Zhao, X. Quinolones: Action and resistance update. Curr. Top. Med. Chem. 2009, 9, 981-998. [CrossRef]

20. Yoshida, H.; Bogaki, M.; Nakamura, M.; Nakamura, S. Quinolone resistance-determining region in the DNA gyrase gyrA gene of Escherichia coli. Antimicrob. Agents Chemother. 1990, 34, 1271-1272. [CrossRef]

21. Willmott, C.J.; Maxwell, A. A single point mutation in the DNA gyrase A protein greatly reduces binding of fluoroquinolones to the gyrase-DNA complex. Antimicrob. Agents Chemother. 1993, 37, 126-127. [CrossRef]

22. Baucheron, S.; Tyler, S.; Boyd, D.; Mulvey, M.R.; Chaslus-Dancla, E.; Cloeckaert, A. AcrAB-TolC directs efflux-mediated multidrug resistance in Salmonella enterica serovar Typhimurium DT104. Antimicrob. Agents Chemother. 2004, 48, 3729-3735. [CrossRef] [PubMed]

23. Blair, J.M.A.; Bavro, V.N.; Ricci, V.; Modi, N.; Cacciotto, P.; Kleinekathofer, U.; Ruggerone, P.; Vargiu, A.V.; Baylay, A.J.; Smith, H.E.; et al. AcrB drug-binding pocket substitution confers clinically relevant resistance and altered substrate specificity. Proc. Natl. Acad. Sci. USA 2015, 112, 3511-3516. [CrossRef] [PubMed]

24. Vidovic, S.; An, R.; Rendahl, A. Molecular and physiological characterization of fluoroquinolone-highly resistant Salmonella Enteritidis strains. Front. Microbiol. 2019, 10, 729. [CrossRef]

25. Hartog, E.; Ben-Shalom, L.; Shachar, D.; Matthews, K.R.; Yaron, S. Regulation of marA, soxS, rob, acr AB, and micF in Salmonella enterica serovar Typhimurium. Microbiol. Immunol. 2008, 52, 565-574. [CrossRef] [PubMed]

26. Mcmurry, L.M.; Oethinger, M.; Levy, S.B. Overexpression of marA, soxS, or acrAB produces resistance to triclosan in laboratory and clinical strains of Escherichia coli. FEMS Microbiol. Lett. 1998, 166, 305-309. [CrossRef] [PubMed]

27. Ruiz, C.; Levy, S.B. Regulation of $a c r A B$ expression by cellular metabolites in Escherichia coli. J. Antimicrob. Chemother. 2014, 69, 390-399. [CrossRef]

28. Rosenberg, E.Y.; Bertenthal, D.; Nilles, M.L.; Bertrand, K.P.; Nikaido, H. Bile salts and fatty acids induce the expression of Escherichia coli AcrAB multidrug efflux pump through their interaction with Rob regulatory protein. Mol. Microbiol. 2003, 48, 1609-1619. [CrossRef]

29. Olliver, A.; Valle, M.; Chaslus-Dancla, E.; Cloeckaert, A. Role of an acrR mutation in multidrug resistance In Vitro-selected fluoroquinolone-resistant mutants of Salmonella enterica serovar Typhimurium. FEMS Microbiol. Lett. 2004, 238, 267-272.

30. Baucheron, S.; Le Hello, S.; Doublet, B.; Giraud, E.; Weill, F.X.; Cloeckaert, A. ramR mutations affecting fluoroquinolone susceptibility in epidemic multidrug-resistant Salmonella enterica serovar Kentucky ST198. Front. Microbiol. 2013, 4, 213. [CrossRef]

31. Vidovic, S.; Medihala, P.; Dynes, J.J.; Daida, P.; Vujanovic, V.; Hitchcock, A.P.; Shetty, D.; Zhang, H.; Brown, D.R.; Lawrence, J.R.; et al. Importance of the RpoE regulon in maintaining the lipid bilayer during antimicrobial treatment with the polycationic agent, chlorhexidine. Proteomics 2018, 18, 1-9. [CrossRef]

32. Guo, M.S.; Updegrove, T.B.; Gogol, E.B.; Shabalina, S.A.; Gross, C.A.; Storz, G. MicL, a new $\sigma^{\mathrm{E}}$-dependent sRNA, combats envelope stress by repressing synthesis of Lpp, the major outer membrane lipoprotein. Genes Dev. 2014, 28, 1620. [CrossRef] [PubMed]

33. Papenfort, K.; Pfeiffer, V.; Mika, F.; Lucchini, S.; Hinton, J.C.D.; Vogel, J. $\sigma^{\mathrm{E}}$-dependent small RNAs of Salmonella respond to membrane stress by accelerating global omp mRNA decay. Mol. Microbiol. 2006, 62, 1674. [CrossRef] [PubMed]

34. Udekwu, K.I.; Gerhart, E.; Wagner, H. Sigma E controls biogenesis of the antisense RNA MicA. Nucleic Acids Res. 2007, 35, 1279. [CrossRef] [PubMed] 
35. Von Eiff, C.; Friedrich, A.W.; Becker, K.; Peters, G. Comparative In Vivo activity of ceftobiprole against staphylococci displaying normal and small-colony variant phenotypes. Antimicrob. Agents Chemother. 2005, 49, 4372-4374. [CrossRef]

36. Bates, D.M.; von Eiff, C.; McNamara, P.J.; Peters, G.; Yeaman, M.R.; Bayer, A.S.; Proctor, R.A. Staphylococcus aureus menD and hemB mutants are as infective as the parent strains, but the menadione biosynthetic mutant persists within the kidney. J. Infect. Dis. 2003, 187, 1654-1661. [CrossRef]

37. Clements, M.O.; Watson, S.P.; Poole, R.K.; Foster, S.J. CtaA of Staphylococcus aureus is required for starvation survival, recovery, and cytochrome biosynthesis. J. Bacteriol. 1999, 181, 501-507. [CrossRef]

38. Cano, D.A.; Pucciarelli, M.G.; Martinez-Moya, M.; Casadesus, J.; Garcia-del Portillo, F. Selection of small-colony variants of Salmonella enterica serovar Typhimurium in nonphagocytic eukaryotic cells. Infect. Immun. 2003, 71, 3690-3698. [CrossRef]

39. Sadowska, B.; Bonar, A.; von Eiff, C.; Proctor, R.A.; Chmiela, M.; Rudnicka, W.; Rozalska, B. Characteristics of Staphylococcus aureus, isolated from airways of cystic fibrosis patients, and their small colony variants. FEMS Immunol. Med. Microbiol. 2002, 18, 191-197. [CrossRef]

40. McNamara, P.J.; Proctor, R.A. Staphylococcus aureus small colony variants, electron transport and persistent infections. Int. J. Antimicrob. Agents 2000, 14, 117-122. [CrossRef]

41. Johns, B.E.; Purdy, K.J.; Tucker, P.N.; Maddocks, S.E. Phenotypic and genotypic characteristics of small colony variants and their role in chronic infection. Microbiol. Insights 2015, 8, 15-23. [CrossRef]

42. Spanu, T.; Romano, L.; D’Inzeo, T.; Masucci, L.; Albanese, A.; Papacci, F.; Marchese, E.; Sanguinetti, M.; Fadda, G. Recurrent ventriculoperitoneal shunt infection caused by small-colony variants of Staphylococcus aureus. Clin. Infect. Dis. 2005, 41, 48-52. [CrossRef] [PubMed]

43. Kim, N.H.; Kang, Y.M.; Han, W.D.; Park, K.U.; Park, K.H.; Yoo, J.I.; Lee, D.G.; Park, C.; Song, K.H.; Kim, E.S.; et al. Small-Colony variants in persistent and recurrent Staphylococcus aureus bacteremia. Microb. Drug Resist. 2016, 22, 538-544. [CrossRef] [PubMed]

44. Kahl, B.C.; Becker, K.; Löffler, B. Clinical significance and pathogenesis of staphylococcal small colony variants in persistent infections. Clin. Microbiol. Rev. 2016, 29, 401-427. [CrossRef] [PubMed]

45. Von Wintersdorff, C.J.H.; Penders, J.; van Niekerk, J.M.; Mills, N.D.; Majumder, S.; van Alphen, L.B.; Savelkoul, P.H.M.; Wolffs, P.F.G. Dissemination of antimicrobial resistance in microbial ecosystems through horizontal gene transfer. Front. Microbiol. 2016, 7, 173. [CrossRef]

46. Canton, R.; Coque, T.M. The CTX-M ß-lactamase pandemic. Curr. Opin. Microbiol. 2006, 9, 466-475. [CrossRef]

47. Poirel, L.; Potron, A.; Nordmann, P. OXA-48-like carbapenemases: The phantom menace. J. Antimicrob. Chemother. 2012, 67, 1597-1606. [CrossRef]

48. Poirel, L.; Liard, A.; Rodriguez-Martinez, J.M.; Nordmann, P. Vibrionaceae as a possible source of Qnr-like quinolone resistance determinants. J. Antimicrob. Chemother. 2005, 56, 1118-1121. [CrossRef]

49. Gillings, M.R. Integrons: Past, present, and future. Microbiol. Mol. Biol. Rev. 2014, 78, 257-277. [CrossRef]

50. Cury, J.; Jove, T.; Touchon, M.; Neron, B.; Rocha, E.P.C. Identification and analysis of integrons and cassette arrays in bacterial genomes. Nucleic Acids Res. 2016, 44, 4539-4550. [CrossRef]

51. Partridge, S.R.; Tsafnat, G.; Coiera, E.; Iredell, J.R. Gene cassettes and cassette arrays in mobile resistance integrons. FEMS Microbiol. Rev. 2009, 33, 757-784. [CrossRef]

52. Swann, M.M.; Baxter, K.L.; Field, H.I.; Howie, J.W.; Lucas, I.A.M.; Millar, E.L.M.; Murdoch, J.C.; Parsons, J.H.; White, E.G. Report of the Joint Committee on the Use of Antibiotics in Animal Husbandry and Veterinary Medicine; Her Majesty's Stationary Office: London, UK, 1969.

53. Castanon, J.I.R. History of the use of antibiotic as growth promoters in European poultry feeds. Poult. Sci. 2007, 86, 2466-2471. [CrossRef] [PubMed]

54. Tang, K.L.; Caffrey, N.P.; Nobrega, D.B.; Cork, S.C.; Ronksley, P.E.; Berkema, H.W.; Polachek, A.J.; Ganshorn, H.; Sharma, N.; Kellner, J.D.; et al. Restricting the use of antibiotics in food-producing animals and its associations with antibiotic resistance in food-producing animals and human beings: A systematic review and meta-analysis. Lancet Planet. Health 2017, 1, e316-e327. [CrossRef]

55. Scott, A.M.; Beller, E.; Glasziou, P.; Clark, J.; Ranakusuma, R.W.; Byambasuren, O.; Bakhit, M.; Page, S.W.; Trott, D.; Mar, C.D. Is antimicrobial administration to food animals a direct threat to human health? A rapid systematic review. Int. J. Antimicrob. Agents 2018, 52, 316-323. [CrossRef] [PubMed] 
56. McEwen, S.A.; Angulo, F.J.; Collignon, P.J.; Conly, J.M. Unintended consequences associated with national-level restrictions on antimicrobial use in food-producing animals. Lancet Planet. Health 2018, 2, e279-e282. [CrossRef]

57. The World Health Organization. Impacts of Antimicrobial Growth Promoter Termination in Denmark. The WHO International Review Panel's Evaluation of the Termination of the Use of Antimicrobial Growth Promoters in Denmark: Foulum, Denmark 6-9 November 2002. 2003. Available online: https://apps.who.int/ iris/handle/10665/68357 (accessed on 24 January 2020).

58. Wierup, M. The Swedish experience of the 1986 year ban of antimicrobial growth promoters, with special reference to animal health, disease prevention, productivity, and usage of antimicrobials. Microb. Drug Resist. 2001, 7, 183-190. [CrossRef]

59. Grave, K.; Jensen, V.F.; Odensvik, K.; Wierup, M.; Bangen, M. Usage of veterinary therapeutic antimicrobials in Denmark, Norway and Sweden following termination of antimicrobial growth promoter use. Prev. Vet. Med. 2006, 75, 123-132. [CrossRef]

60. Arnold, S.; Gassner, B.; Giger, T.; Zwahlen, R. Banning antimicrobial growth promoters in feedstuffs does not result in increased therapeutic use of antibiotics in medicated feed in pig farming. Pharmacoepidemiol. Drug Saf. 2004, 13, 323-331. [CrossRef]

61. Nadimpalli, M.L.; Stewart, J.R.; Pierce, E.; Pisanic, N.; Love, D.C.; Hall, D.; Larsen, J.; Caroll, K.C.; Tekle, T.; Perl, T.M.; et al. Face mask use and persistence of livestock-associated Staphylococcus aureus nasal carriage among industrial hog operation workers and household contacts, USA. Environ. Health Perspect. 2018, 126, 127005. [CrossRef]

62. Nadimpalli, M.L.; Stewart, J.R.; Pierce, E.; Pisanic, N.; Love, D.C.; Hall, D.; Larsen, J.; Caroll, K.C.; Tekle, T.; Perl, T.M.; et al. Livestock-Associated, antibiotic-resistant Staphylococcus aureus nasal carriage and recent skin and soft tissue infection among industrial hog operation workers. PLoS ONE 2016, 11, e0165713. [CrossRef]

63. Jackson, J.; Villarroel, A. A survey of the risk of zoonoses for veterinarians. Zoonoses Public Health 2012, 59, 193-201. [CrossRef]

64. Levy, S.B.; Fitzgerald, G.B.; Macone, A.B. Spread of antibiotic-resistant plasmids from chicken to chicken and from chicken to man. Nature 1976, 260, 40-42. [CrossRef]

65. Vidovic, S.; Korber, D.R. Prevalence of Escherichia coli O157 in Saskatchewan cattle: Characterization of isolates by using random amplified polymorphic DNA PCR, antibiotic resistance profiles and pathogenicity determinants. Appl. Environ. Microbiol. 2006, 72, 4347-4355. [CrossRef]

66. Thanner, S.; Drissner, D.; Walsh, F. Antimicrobial resistance in agriculture. mBio 2016, 7, e02227-15. [CrossRef]

67. Madsen, A.M.; Kurdi, I.; Feld, L.; Tendal, K. Airborne MRSA and total Staphylococcus aureus as associated with particles of different sizes on pig farms. Ann. Work Expo. Health 2018, 62, 966-977. [CrossRef]

68. Aires-de-Sousa, M. Methicillin-Resistant Staphylococcus aureus among animals: Current overview. Clin. Microbiol. Infect. 2017, 23, 373-380. [CrossRef]

69. Kock, R.; Schaumburg, F.; Mellmann, A.; Koksal, M.; Jurke, A.; Becker, K.; Friedrich, W.A. Livestock-Associated methicillin-resistant Staphylococcus aureus (MRSA) as causes of human infection and colonization in Germany. PLoS ONE 2013, 8, e55040. [CrossRef]

70. Harrison, E.M.; Paterson, G.K.; Holden, M.T.G.; Larsen, J.; Stegger, M.; Larsen, A.R.; Petersen, A.; Skov, R.L.; Christensen, J.M.; Zeuthen, A.B.; et al. Whole genome sequencing identifies zoonotic transmission of MRSA isolates with the novel mecA homologue mecC. EMBO Mol. Med. 2013, 5, 509-515. [CrossRef]

71. Chen, M.; Qiu, T.; Sun, Y.; Song, Y.; Wang, X.; Gao, M. Diversity of tetracycline-and erythromycin-resistant bacteria in aerosols and manures from four types of animal farms in China. Environ. Sci. Pollut. Res. 2019, 26, 24213-24222. [CrossRef]

72. An, R.; Alshalchi, S.; Breimhurst, P.; Munoz-Aguayo, J.; Flores-Figueroa, C.; Vidovic, S. Strong influence of livestock environments on the emergence and dissemination of distinct multidrug-resistant phenotypes among the population of non-typhoidal Salmonella. PLoS ONE 2017, 12, e0179005. [CrossRef]

73. Mather, A.E.; Reid, S.W.J.; Maskell, D.J.; Parkhill, J.; Fookes, M.C.; Harris, S.R.; Brown, D.J.; Coia, J.E.; Mulvey, M.R.; Gilmour, M.W.; et al. Distinguishable epidemics of multidrug-resistant Salmonella Typhimurium DT104 in different hosts. Science 2013, 341, 514-517. [CrossRef] 
74. Ludden, C.; Raven, K.E.; Jamrozy, D.; Gouliouris, T.; Blane, B.; Coll, F.; de Goffau, M.; Naydenova, P.; Horner, C.; Harnandez-Garcia, J.; et al. One health genomic surveillance of Escherichia coli demonstrates distinct linages and mobile genetic elements in isolates from human versus livestock. mBio 2019, 10, e02693-18. [CrossRef] [PubMed]

75. Bogdanovic, U.; Lazic, V.; Vodnik, V.; Budimir, M.; Markovic, Z.; Dimitrijevic, S. Copper nanoparticles with high antimicrobial activity. Mater. Lett. 2014, 128, 75-78. [CrossRef]

76. Perelshtein, I.; Ruderman, Y.; Perkas, N.; Beddow, J.; Singh, G.; Vinatoru, M.; Joyce, E.; Mason, T.J.; Blanes, M.; Molla, K.; et al. The sonochemical coating of cotton withstands 65 washing cycles at hospital washing standards and retain its antimicrobial properties. Cellulose 2013, 20, 1215-1221. [CrossRef]

77. Vidovic, S.; Elder, J.; Medihala, P.; Lawrence, J.R.; Predicala, B.; Zhang, H.; Korber, D.R. ZnO nanoparticles impose a panmetabolic toxic effect along with strong necrosis, inducing activation of the envelope stress response in Salmonella enterica serovar Enteriditis. Antimicrob. Agents Chemother. 2015, 59, 3317-3328. [CrossRef]

78. Jones, N.; Ray, B.; Ranjit, K.T.; Manna, A.C. Antimicrobial activity of ZnO nanoparticle suspensions on a broad spectrum of microorganisms. FEMS Microbiol. Lett. 2008, 279, 71-76. [CrossRef]

79. Reddy, K.M.; Feris, K.; Bell, J.; Wingett, D.G.; Hanley, C.; Punnoose, A. Selective toxicity of zinc oxide nanoparticles to prokaryotic and eukaryotic systems. Appl. Phys. Lett. 2007, 90, 213902-213905. [CrossRef]

80. Malka, E.; Perelshtein, I.; Lipovsky, A.; Shalom, Y.; Naparstek, L.; Perkas, N.; Patick, T.; Lubart, R.; Nitzan, Y.; Banin, E.; et al. Eradication of multi-drug resistant bacteria by a novel $\mathrm{Zn}$-doped $\mathrm{CuO}$ nanocomposite. Small 2013, 9, 4069-4076. [CrossRef]

81. Kooti, M.; Sedeh, A.N.; Motamedi, H.; Rezatofighi, S.E. Magnetic graphene oxide inlaid with silver nanoparticles as antibacterial and drug delivery composite. Appl. Microb. Biotechnol. 2018, 102, 3607-3621. [CrossRef]

82. Hagens, S.; Loessner, M. Application of bacteriophages for detection and control of foodborne pathogens. Appl. Microbiol. Biotechnol. 2007, 76, 513-519. [CrossRef]

83. PhageGuard. Available online: https://phageguard.com/ (accessed on 14 December 2019).

84. Soni, K.A.; Nannapaneni, R. Removal of Listeria monocytogenes biofilms with bacteriophage P100. J. Food Prot. 2010, 73, 1519-1524. [CrossRef]

85. Iacumin, I.; Manzano, M.; Comi, G. Phage inactivation of Listeria monocytogenes on San Daniele dry-cured ham and elimination biofilms from equipment and working environments. Microorganisms 2016, 4, E4. [CrossRef] [PubMed]

86. Sadekuzzaman, M.; Yang, S.; Mizan, M.F.R.; Kim, H.S.; Ha, S.D. Effectiveness of a phage cocktail as a biocontrol agent against L. monocytogenes biofilms. Food Control 2017, 78, 256-263. [CrossRef]

87. Soni, K.A.; Nannapaneni, R.; Hagens, S. Reduction of Listeria monocytogenes on the surface of fresh channel catfish fillets by bacteriophage Listex P100. Foodborne Pathog. Dis. 2010, 7, 427-434. [CrossRef] [PubMed]

88. Cotter, P.D.; Hill, C.; Ross, R.P. Bacteriocins: Developing innate immunity for food. Nat. Rev. Microbiol. 2005, 3, 777-788. [CrossRef]

89. Breukink, E.; de Kruijff, B. Lipid II as a target for antibiotics. Nat. Rev. Drug Discov. 2006, 5, 321-323. [CrossRef]

90. Machaidze, G.; Seelig, J. Specific binding of cinnamycin (Ro 09-0198) to phospatidylethanolamine. Comparison between micellar and membrane environments. Biochemistry 2003, 42, 12570-12576. [CrossRef] [PubMed]

91. Silva, C.C.G.; Silva, S.P.M.; Ribeiro, S.C. Application of bacteriocins and protective cultures in dairy food preservation. Front. Microbiol. 2018, 9, 594. [CrossRef] [PubMed]

92. Gomez, N.C.; Ramiro, J.M.P.; Quecan, B.X.V.; de Melo Franco, B.D.G. Use of potential probiotic lactic acid bacteria (LAB) biofilms for the control of Listeria monocytogenes, Salmonella Typhimurium, and Escherichia coli O157:H7 biofilms formation. Front. Microbiol. 2016, 7, 863. [CrossRef]

93. Minei, C.C.; Gomes, B.C.; Ratti, R.P.; D'angelis, C.E.M.; DeMartinis, F.C.P. Influence of peroxyacetic acid and nisin and coculture with Enterococcus faecium on Listeria monocytogenes biofilm formation. J. Food Prot. 2008, 71, 634-638. [CrossRef]

94. Alvarez-Sieiro, P.; Montalban-Lopez, M.; Mu, D.; Kuipers, O.P. Bacteriocins of lactic acid bacteria: Extending the family. Appl. Microbiol. Biotechnol. 2016, 100, 2939-2951. [CrossRef] 
95. Harrison, E.M.; Ba, X.; Coll, F.; Blane, B.; Restif, O.; Carvell, H.; Koser, C.U.; Jamrozy, D.; Reuter, S.; Lovering, A.; et al. Genomic identification of cryptic susceptibility to penicillins and $\beta$-lactamase inhibitors in methicillin-resistant Staphylococcus aureus. Nat. Microbiol. 2019, 4, 1680-1691. [CrossRef] [PubMed]

96. Van Boeckel, T.; Brower, C.; Gilbert, M.; Grenfell, B.T.; Levin, S.A.; Robinson, T.P.; Teillant, A.; Laxminarayan, R. Global trends in antimicrobial use in food animals. Proc. Natl. Acad. Sci. USA 2015, 112, 5649-5654. [CrossRef] [PubMed]

97. Van Boeckel, T.; Pires, J.; Silvester, R.; Zhao, C.; Song, J.; Criscuolo, N.G.; Gilbert, M.; Bonhoeffer, S.; Laxminarayan, R. Global trends in antimicrobial resistance in animals in low-and middle-income countries. Science 2019, 365. [CrossRef] [PubMed]

C 2020 by the authors. Licensee MDPI, Basel, Switzerland. This article is an open access article distributed under the terms and conditions of the Creative Commons Attribution (CC BY) license (http://creativecommons.org/licenses/by/4.0/). 